\title{
Improving seismic behaviour of irregular building through double column and console beam application
}

\author{
Ririt Aprilin Sumarsono, ${ }^{1,}$, Muhammad Aji Fajari ${ }^{1}$ \\ ${ }^{1}$ Universitas Negeri Jakarta, Civil Engineering Department, 13220 Rawamangun Muka, Indonesia
}

\begin{abstract}
Recent years, the shape of building is getting sophisticated; otherwise the environmental load such as earthquake, wind, and wave cannot longer be neglected during analysis. Accommodating U-shaped building for analysis, we noticed the irregularity in both horizontal and vertical direction will create severe damages to the structure under the earthquake. In order to prevent destruction to the structural member, assigning dilatation is one possible way by utilizing double column or console beam system to break the irregularity of the building plan. During analysis, the model of non shear wall system is also built in order to compare the effectiveness between both systems. Strong evidence of double column system performance is less than console beam is answered from behavioural parameters of the both system under earthquake. Higher period, displacement and drift are peril for the double column system compare to console beam system application. Hence, console beam system is beneficially selected to solve irregularities in horizontal direction as the discontinuity of the load transfer is relatively small. Hereinafter, installing earthquake resistant system can be reconsidered after the dilatation was applied to strengthen certain direction which was marked as the weak axis of the building structure.
\end{abstract}

Keywords: Horizontal irregularity, vertical irregularity, response spectra, double column, console beam

\section{Introduction}

Architecture plays important role in order to fulfil the artsy building look. Geometry, shape, and size of the building are some main factors that entails seismic structural configuration [1]. Oftentimes, the building shape is not strict and regular anymore which cause irregularities in the floor plan (horizontal) and building height (vertical). During the design, regular plan in both vertical and horizontal will not create problems to the member structure especially due to horizontal load such as earthquake. As the irregularity appears, the structural design will face some problems in the capacity of member structure which is represented in the behaviour of the structure.

Earthquake load which is translated into ground motion data is very useful for the seismic design such as Indonesia. Recent years, some devastating earthquake happened continuously which effect fatalities particularly building structures in some countries like Japan, Italy, and Indonesia. Inadequacy of seismic codes and guidelines in the past has become one of the aspects that led to this fact [2]. Increasing the seismic analysis into more advanced approach can also be the choice to get better result.

Building structure can be detected to have horizontal and/or vertical irregularity which must be directed to certain seismic design category [3]. Some solutions are introduced to strengthen the structure due to earthquake for reinforced concrete building such as shear wall. Traditionally, the use of reinforced concrete shear wall has been common in multi-story building [4]. Clear advantages of shear wall such as easy construction and straight forward detailing makes this system is chosen due to both cost and structural damage minimization. Further, shear wall placement will be more effective when it is located in the exterior perimeter of the building; otherwise core wall is named for the shear wall position in the centre of building plan.

Irregular building with certain earthquake restraining system is required to suppress the seismic load. Other way, we may consider the approximate method to modify the irregular building into regular one. Dilatation has been famous to be put in practice through several ways like double column system, console beam (corbel) system, cantilever beam system, and Gerber beam system. The idea of dilatation is disjointing the building plan notably in the corner section of the floor plan so that the building may behave as regular building. The focus of this paper is application of the double column and console beam system to the irregular multi-story building.

\footnotetext{
* Corresponding author: ririt-aprilin@unj.ac.id (Ririt Aprilin S); ajifajari182@gmail.com (Muhammad Aji Fajari)
} 


\section{Parametric study}

This chapter will provide the information of the building geometry and main properties of the structural member used in this building. Simplifications are made especially for modelization during the analysis using ETABS v.13. Elimination of basement floor plan is applied in order to have the perfect irregular building shape from top floor until the basement. All the results will be based on the simulation analysis, so that the true behaviour of the structure and failure capacity of the member structure cannot be compared with the experiment results yet.

\subsection{Building geometry}

Utilizing U shape building from the Heliconia Apartment Tower of Bassura City which consists of 25 floors as shown in figure 1 is compatible for this paper. Certain floors has different height from the typical $2.7 \mathrm{~m}$ apartment floor such as in the basement (B1), lower ground (LG), ground (GF), and roof floor (RF) which are $3.2 \mathrm{~m}, 3.55 \mathrm{~m}, 3.22 \mathrm{~m}$, and $2.75 \mathrm{~m}$ respectively.

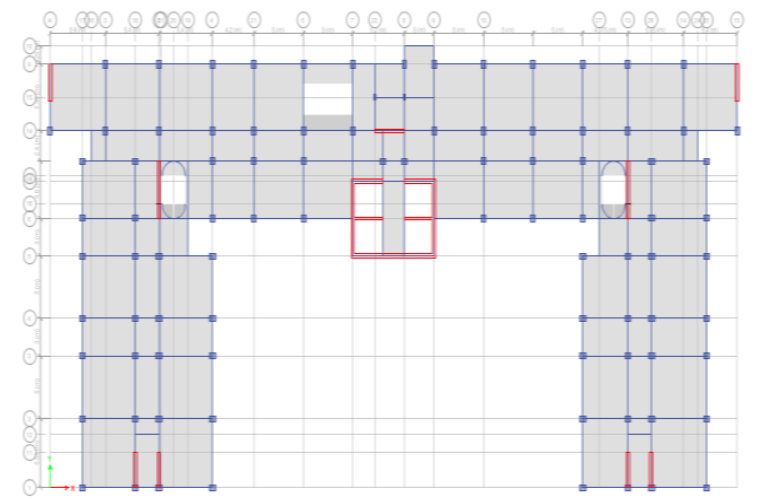

Fig. 1. Building floor plan

Symmetrical floor plan of the $U$ floor plan building is also followed by the shear wall composition of this building (see figure 1 and 2). Later, disjointing the building floor plan through dilatation will only apply once for each direction in both sides as seen in figure 3 .

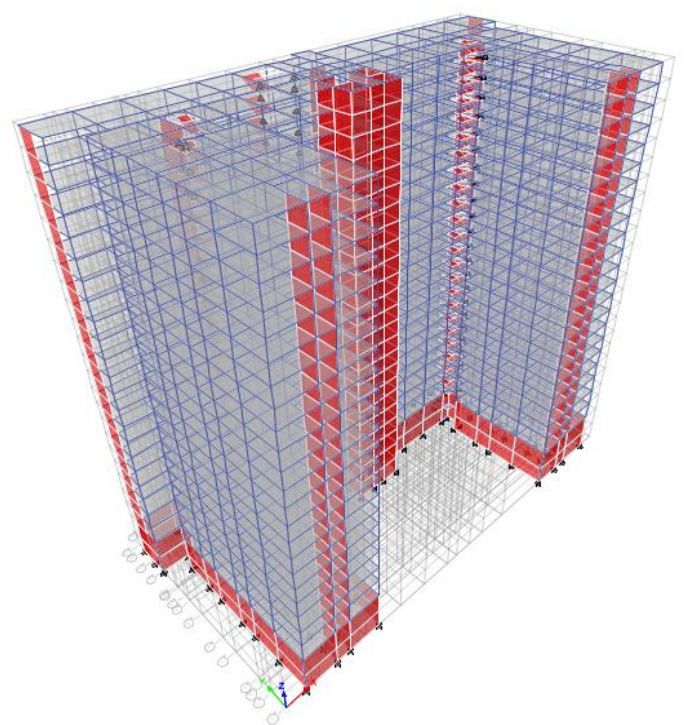

Fig. 2. Isometric of building
Besides the shear wall, there is retaining wall exist at B1 and LG floor (see figure 2) along the perimeter of the building floor plan continuously. Generally, the retaining wall functioned for resisting the soil pressure load, yet it may increase the building stiffness due to earthquake load. Stair and slab is modelled in the building so that it will contribute certain stiffness to the building as well.

\subsection{Member properties}

Reinforced concrete building strengthened with shear wall as seen in figure 1 (red lines) harness different compressive strength of concrete properties based on the structural member which are K350 (34.32 MPa), K400 (39.23 MPa), and K450 (44.13 MPa) for column and shear wall; otherwise K300 (29.42 $\mathrm{MPa}$ ) and K350 (34.32 $M P a)$ for beam, slab, and stair. On the other hand, reinforcing steel used is BJTD 40 (yield strength $=400$ $M P a$ ) for all member structure.

The dimension of the columns varies from $450 \times 1000$ $\mathrm{mm}$ to $450 \times 600 \mathrm{~mm}$. Beams are served with a very high range of the dimension of $300 \times 400 \mathrm{~mm}, 1000 \times 200 \mathrm{~mm}$, $500 \times 700 \mathrm{~mm}$, and so forth. Shear wall thickness is available in $200 \mathrm{~mm}$ and $350 \mathrm{~mm}$ in several places of the perimeter of the building. Last, the slab thickness is occupied with the smallest of $130 \mathrm{~mm}$ and the highest of $200 \mathrm{~mm}$.

\subsection{Load identification}

Several loads for this paper are defined including dead load, live load and earthquake load. Particularly for the basement, soil pressure was assigned as the live load for the basement wall. Additional dead load known as superimposed dead load including the floor cover, flooring mixture, plafond, partition wall, and mechanicalelectrical devices is also considered in the analysis.

Load combinations used in the analysis mainly considered dead load, live load and earthquake load in terms of spectra. The following combinations from reference [3] are harnessed in the ETABS analysis, so that totally 18 load combinations are derived based on the following:

$$
1.4 \mathrm{DL}
$$

$$
1.2 \mathrm{DL}+1.6 \mathrm{LL}
$$

$1.2 D L+1.0 L L \pm 0.3\left(\rho Q_{E X}+0.2 S_{D S} D L\right) \pm 1.0\left(\rho Q_{E Y}\right.$

$$
\left.+0.2 S_{D S} D L\right)
$$

$$
1.2 D L+1.0 L L \pm 1.0\left(\rho Q_{E X}+0.2 S_{D S} D L\right) \pm 0.3\left(\rho \mathrm{Q}_{E Y}\right.
$$$$
\left.+0.2 S_{D S} D L\right)
$$

$0.9 D L \pm 0.3\left(\rho Q_{E X}-0.2 S_{D S} D L\right) \pm 1.0\left(\rho Q_{E Y}-0.2 S_{D S}\right.$

$$
D L)
$$

$$
0.9 D L \pm 1.0\left(\rho Q_{E X}-0.2 S_{D S} D L\right) \pm 0.3\left(\rho Q_{E Y}-0.2 S_{D S}\right.
$$

$$
D L)
$$

Site class of this building can be categorized as site class $\mathrm{C}$ with the soil condition of hard soil. The characteristics of the site effect the duration and frequency of earthquake ground motion. In general, structures founded on hard soil to rock will be subjected to shortperiod (high frequency) motion [5]. The acceleration ground motion of certain site class will be served in 
response spectra as the seismic analysis used in this paper is linear dynamic response spectra for both $X$ and $Y$ direction of building floor plan.

\section{Analysis parameter}

\subsection{Irregularities}

Vertically irregular building must satisfy the strong column-weak beam concept in order to reach structural safety [6]. The column stiffness plays important role in order to detain the earthquake load due to the presence of vertical irregularity. On the other hand, horizontal irregularity causes the division of earthquake load to the direction of the floor plan which means all the direction will suffer horizontal load equally. Consequently, the strong axis of the building plan absorbs more earthquake load than weak axis can resist.

Analyzing the building plan, it is clear that the horizontal and vertical irregularities exist. Re-entrant corner is simply detected from the typical floor plan, conversely variation of floor height results stiffness problem denoted as soft story problem especially in B1, LG and $\mathrm{G}$ floor.

Preliminary, the percentage of re-entrant corner is $48 \%$ and $63 \%$ respectively in $X$ and $Y$ direction. By considering dilatation, the expectation of separating the building into several regular building can be achieved. However, it will not be definitely reduce the re-entrant corner percentage. As the building is disjointed into several cuts as seen in figure 3, M1 and M3 will still emerge the re-entrant issue compare to M2 and M4. Model M1 results higher re-entrant corner percentage into $74 \%$ in $\mathrm{X}$ direction, whereas M4 rises up into $65 \%$.

\subsection{Variations of modelization}

Application of double column and console beam system in the following four different building cuts of the floor plan of the building can be referred in figure 3. Model M1 and M3 still remain irregular building in horizontal direction, whereas model M2 and M4 result independent regular building due to disjointing the floor plan. Otherwise, console beam kept the building remain the same existing as we modified the restraint of one-end joint to be free to move in horizontal direction.
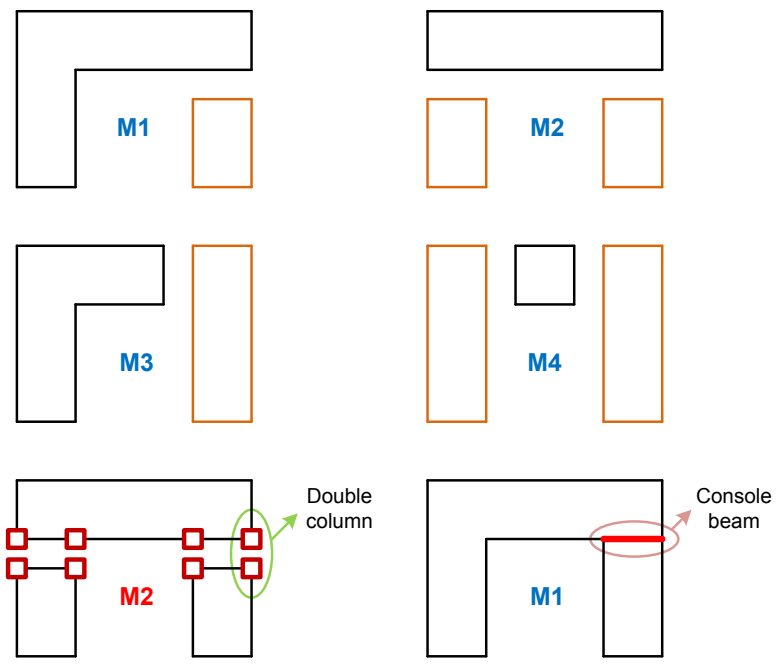

Fig. 3. Variation of disjoint building floor plan

Double column system has the consequence of the extra column built after separating the floor plan. The distance between two new built columns is set to be $3 \mathrm{~m}$ for M3 and M4 and $5 m$ for M1 and M2 due to beam deletion. The prominent judgement of the distance is providing enough space for the building to reach maximum displacement at the roof floor. Majority, the choice of double column system will affect the structural mass due to elimination of beams.

Further concern of analysis by using double column system in ETABS is still utilizing one input of earthquake load so that the result for each model will result as one system of building plan. The experiment of fully separated building floor plan will not be performed and analyzed in this paper

Modification of beam-column joint can be formatted by constructing console (corbel). Corbel is the bracket that project from the face of the column to support primary beam and girder [7]. Discontinuity of beam to column by using corbel can be fulfilled to create separation of irregular building floor plan.

Henceforth, idealization of the console beam is done by releasing one end-restrain of the beam which is connected to the column. Translational and displacement in $X$ and $Y$ direction are applied to the console beam system modelization.

\subsection{Response spectra}

A plot of maximum acceleration, velocity, or displacement for single degree of freedom oscillator as a function of system period, for a given input motion and system damping is called response spectra [8]. After identifying the site class, the $\mathrm{S}_{D S}$ and $\mathrm{S}_{D 1}$ parameter is recorded $0.516 \mathrm{~g}$ and $0.301 \mathrm{~g}$ respectively which output of response spectra is shown in figure 4. 


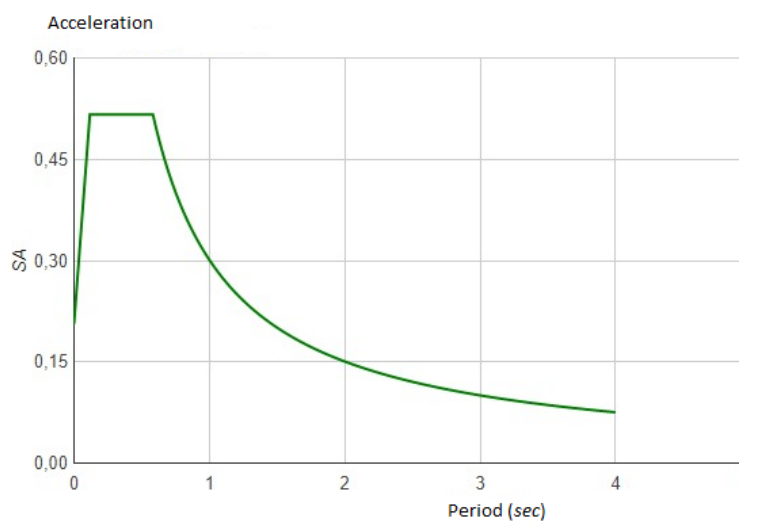

Fig. 4. Response spectra acceleration for site class C

As mentioned before, identification of the site class will determine the response spectra which procedure of building the spectra known as site-specific response spectra. In the case of local soil conditions are not amenable to simple classification; the use of smooth spectra curves is inadequate [9].

\section{Result discussions}

\subsection{Behaviour of structure}

After completing the analysis, there are basics of data that we can select for further discussion. Especially for the earthquake analysis, we will concern on the period, mass, base shear, displacement and drift in both direction as the overview of structural behaviour. Due to 18 combinations occupied in this paper, massive analysis and recap has been conducted in order to direct the whole discussion into one most critical load combination results which is combination 3 . The first mode of the structural response is also preferred for being thoroughly examined.

\subsubsection{Period of structure}

Existing building (E-SW) delivers the period of $0.237 \mathrm{sec}$, whilst $0.239 \mathrm{sec}$ is reported for the existing building without shear wall (E-NSW). The shear wall increased a very slight period of structure so that the uniformity and symmetry of building plan has been reached. Uniform existing building creates uniform distribution of mass, strength, and stiffness. Moreover, structural symmetry means the centre of mass and centre of resistance are located at, or close to, the same point [5].

It is interesting that the double column (DC) system serves higher fundamental period of structure than the existing building even without shear wall (E-NSW). All the variation models (M1 to M4) has bigger difference once the horizontal irregularity is decreased as shown in M3 and M4. It is clearly noticed that the strong axis of the floor plan in $X$ direction. M1 and M2 still provide higher percentage of re-entrant corner irregularity than M3 and M4.

From table 1, it informs that console beam (CB) perform faster time in order to go back to initial state. Installation of resisting earthquake system such as shear wall (SW) has caused reduction on period. The greater deviation can be seen in M4 which is concluded that releasing more restraint in some places of the beam in a weak axis of building plan will result higher period of structure.

Table 1. Period of structure (sec)

\begin{tabular}{|c|c|c|c|}
\hline \multicolumn{2}{|c|}{ Modelization } & $\begin{array}{c}\text { Double } \\
\text { Column } \\
\text { (DC) }\end{array}$ & $\begin{array}{c}\text { Console } \\
\text { Beam } \\
\text { (CB) }\end{array}$ \\
\hline \multirow{4}{*}{$\begin{array}{c}\text { Shear Wall } \\
(\mathrm{SW})\end{array}$} & $\mathrm{M} 1$ & 2.078 & 0.237 \\
\cline { 2 - 4 } & $\mathrm{M} 2$ & 2.113 & 0.237 \\
\cline { 2 - 4 } & $\mathrm{M} 3$ & 1.146 & 0.237 \\
\cline { 2 - 4 } & $\mathrm{M} 4$ & 1.160 & 0.270 \\
\hline \multirow{2}{*}{$\begin{array}{c}\text { Non Shear } \\
\text { Wall } \\
(\mathrm{NSW})\end{array}$} & $\mathrm{M} 1$ & 2.053 & 0.239 \\
\cline { 2 - 4 } & $\mathrm{M} 2$ & 2.088 & 0.239 \\
\cline { 2 - 4 } & $\mathrm{M} 3$ & 1.014 & 0.239 \\
\cline { 2 - 4 } & $\mathrm{M} 4$ & 1.029 & 0.278 \\
\hline
\end{tabular}

\subsubsection{Mass of structure}

Simulation performs SW and NSW for both DC and CB system which influence the total mass of structure. Noting that DC system bring the impact of lower mass, but the modelization process can be definitely confidence of getting the same ratio between SW and NSW model compare to $\mathrm{CB}$ system which is about $7 \%$ deviation of mass. Comparing the mass results for all models in table 2 , it has been successfully analogue with the existing building between E-SW and E-NSW.

Based on that, the other results can be trustworthy to be compared and analyzed as the summary. Period result has proven higher period for lower mass rather that bigger mass. Next, the base shear and displacement value can be discussed further.

Table 2. Mass of Structure $(\mathrm{kg})$

\begin{tabular}{|c|c|c|c|}
\hline \multicolumn{2}{|c|}{ Modelization } & $\begin{array}{c}\text { Double } \\
\text { Column } \\
\text { (DC) }\end{array}$ & $\begin{array}{c}\text { Console } \\
\text { Beam } \\
\text { (CB) }\end{array}$ \\
\hline \multirow{4}{*}{$\begin{array}{c}\text { Shear Wall } \\
(\text { SW) }\end{array}$} & M1 & 27980099.56 & 28433302.46 \\
\cline { 2 - 4 } & M2 & 27533110.19 & 28433341.22 \\
\cline { 2 - 4 } & M3 & 27728721.99 & 28434410.38 \\
\cline { 2 - 4 } & M4 & 27141300.82 & 28142052.35 \\
\hline \multirow{2}{*}{$\begin{array}{c}\text { Non Shear } \\
\text { Wall } \\
(\text { NSW) }\end{array}$} & M1 & 25829217.39 & 26280652.06 \\
\cline { 2 - 4 } & M2 & 25384012.16 & 26280706.62 \\
\cline { 2 - 4 } & M3 & 25576055.71 & 26281744.15 \\
\cline { 2 - 4 } & M4 & 24988634.57 & 25989386.05 \\
\hline
\end{tabular}

\subsubsection{Base shear}

Representation of the earthquake load to the building resistance is indicated by the base shear value. Structural configuration can lead to higher or lower design base shear corresponding to redundancy factor [10]. Strong axis of the building will result higher base shear, so that from figure 5 and 6 can be described significant variance of base shear value in both DC and CB system with SW. The same result also occurs for NSW, where base shear in $X$ direction is almost 3 times greater than $Y$ direction for DC system. In the opposite, CB system is almost 12 times larger value in $X$ direction corresponding to $Y$ direction. 
Emphasis of the irregularity issue for DC system, all the variation model varies in base shear value for both directions. It is implied that percentage of irregularity and group of regular building under one analysis will still be considered as irregular. Different result conveyed from CB system, where weak axis will act worse as the discontinuity applied in that direction.

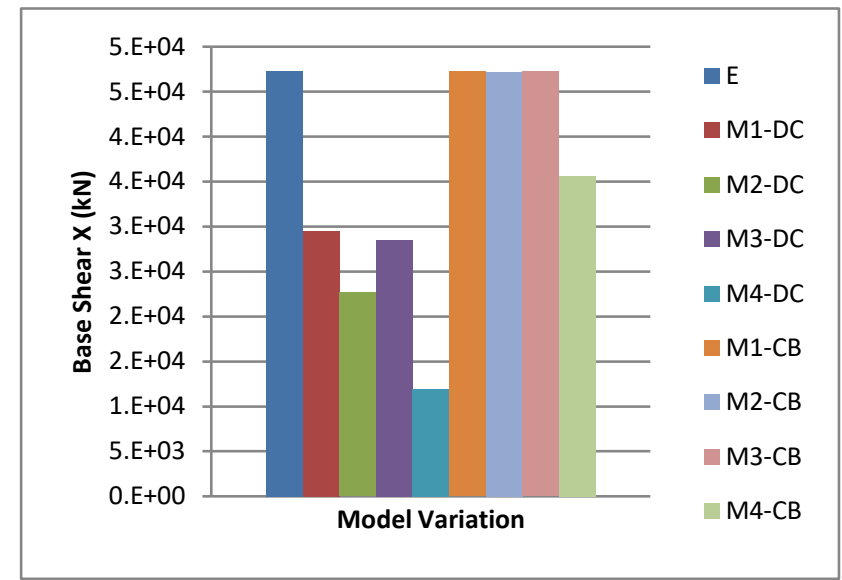

Fig. 5. Base shear in $X$ direction for model with SW

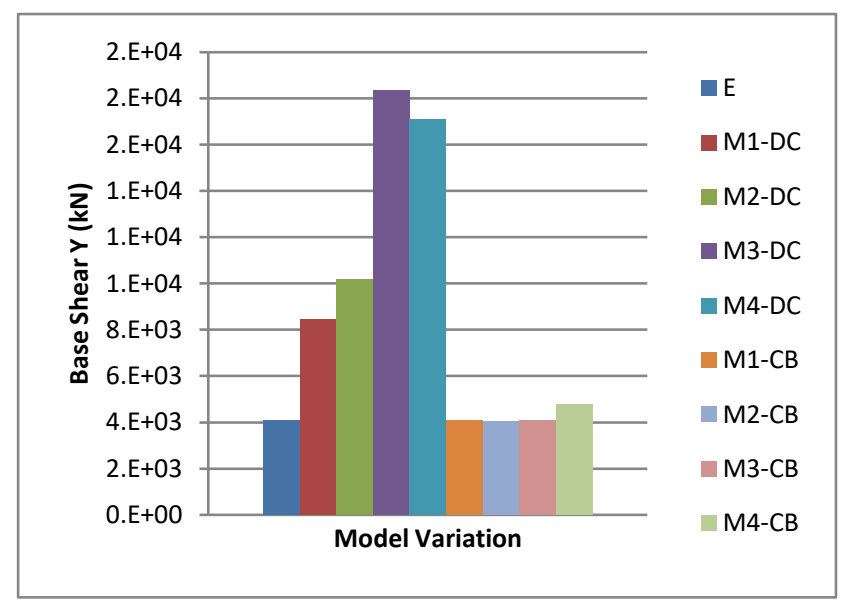

Fig. 6. Base shear in $Y$ direction for model with SW

If we look up further for SW and NSW result for base shear, DC-SW will provide less resistance than DC-NSW system. On the contrary, CB system agrees officially to work for giving more resistance to the building under earthquake. Notion of the irregularity issue in DC system leads to the result where M1 and M3 provides lower performance as the irregularity still exists, otherwise M2 and M4 indicates better performance.

\subsubsection{Displacement and drift}

Drift is generally defined as the lateral displacement of one floor relative to the floor below. Total building drift is the absolute displacement of any point relative to the base [9]. Both model of SW and NSW for all variation model of DC and CB system are referred to figure 7 and 8 for the displacement $X$ result. The displacement $\mathrm{Y}$ is varied from one third to half of displacement $X$ for DCSW and DC-NSW system, whereas CB-SW to CB-NSW correspond almost the same ratio as DC system.

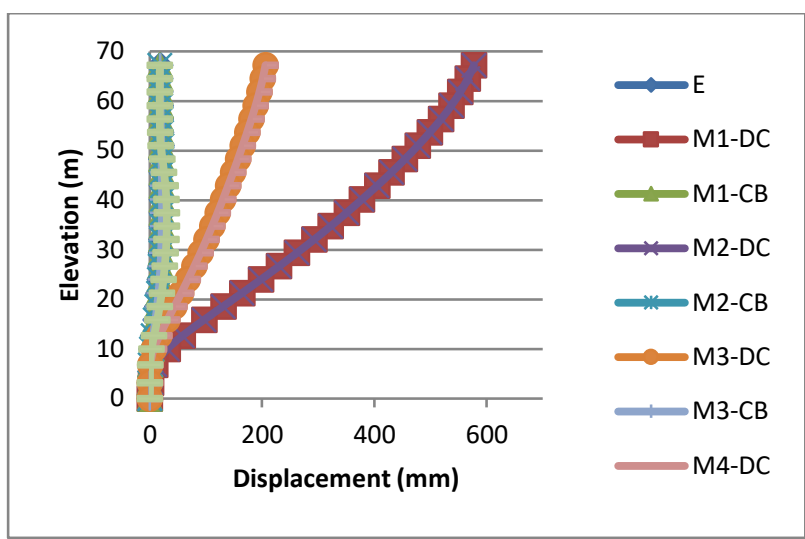

Fig. 7. Displacement $X$ for SW model

Existing building as the reference indicates better result in most parameters discussed, even displacement is far below the limit of $134 \mathrm{~mm}$. The same for CB system which produce safe displacement value as the existing building, moreover CB-NSW still performs best under earthquake.

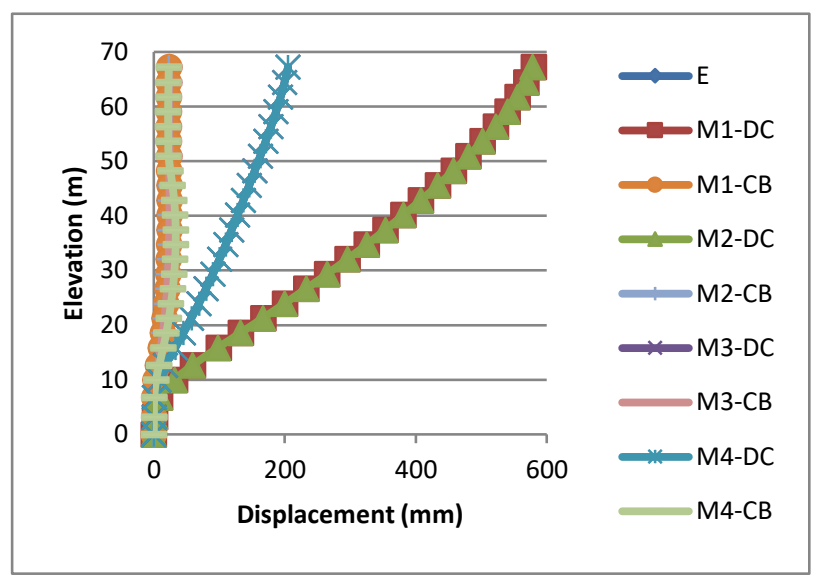

Fig. 8. Displacement $X$ for N-SW model

If there is discontinuity in the load path, the building is unable to resist seismic forces regardless of the strength of the elements [9]. It verifies that larger column distance for DC system will result higher displacement as the building height increases. From figure 7 and 8, installing shear wall will not increase the stiffness significantly to building system. Percentage of irregularities in the strong axis direction is the best answer that influences the displacement of the structure. The lower irregularities will result smaller total displacement of the structure.

In contrary, $\mathrm{CB}$ system particularly in certain change of floor height points out higher drift as seen in figure and 10 . The abrupt change in rigidity due to significant story height will affect the distributions of shear forces [11]. Soft story must take into consideration for applying CB system as the column stiffness inclines. 


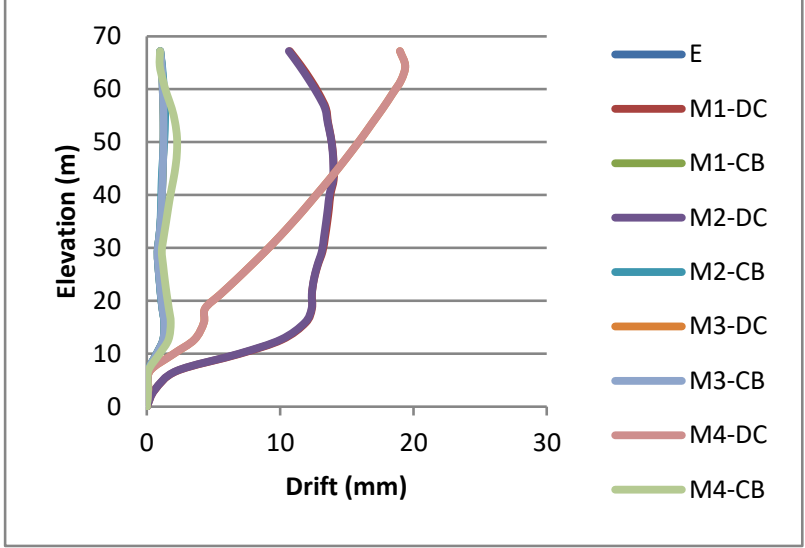

Fig. 9. Drift $X$ for SW model

Increasing of the drift for both directions $(X$ and $Y)$ is explicitly seen for DC system as the story number increases around ten times of the existing building drift. The irregularity in horizontal direction is fail to be maintained by applying DC system moreover if the direction of the dilatation given will remain the same high percentage of irregularity as the existing building. Severe condition will be resulted as the weak axis of the building is not strengthened with earthquake resistant system.

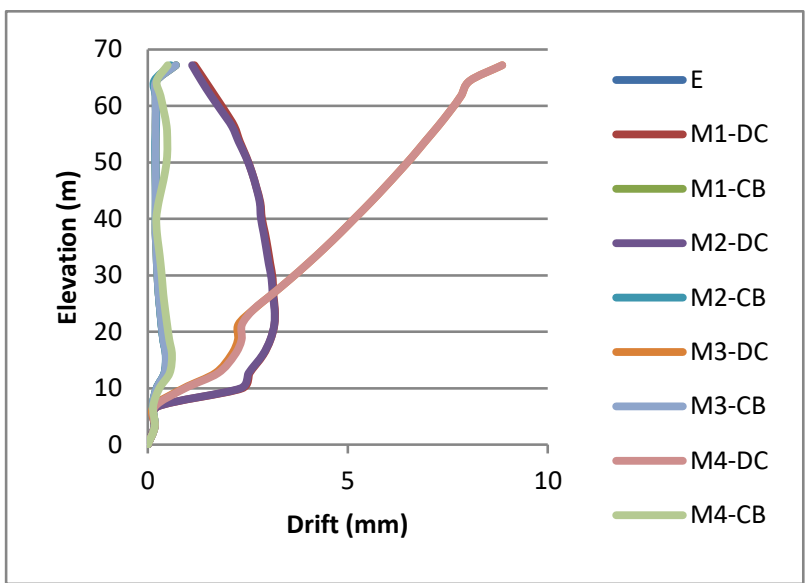

Fig. 10. Drift $Y$ for SW model

We may conclude that DC system has less stiffness due to lower mass compare to existing building. The fact of distance lies between columns to minimize the irregularities has raised another distinct fact on why DC system performance is less than CB system. The main concern for DC system could be resolved by seeing individual performance of building section after disjointed.

\subsection{Capacity of member structure}

Performance of the structural member is presented in terms of moment and shear capacity for member in flexure such as beam. Axial force and moment capacity will be provided for describing column strength.

\subsubsection{Column capacity}

Interaction diagram of column is informative to further analyze the capacity of column under external loading.
Plan irregularities, on the other hand, cause non-uniform demand-to-capacity ratio amongst the column within a single floor [12].

Focus of the discussion will be limited to column type $\mathrm{K} 1 \mathrm{H}$ and the column number $\mathrm{C} 9, \mathrm{C} 57$, and $\mathrm{C} 79$ which is further examined its performance in $\mathrm{B} 1,15 \mathrm{~F}$ and $\mathrm{RF}$ position. The index of $\mathrm{C} 9, \mathrm{C} 57$, and $\mathrm{C} 79$ can be referred in figure 11 which is selected to be the critical values of column capacity. Some of them are out from the interaction diagram which is noted to fail under external load including seismic load.

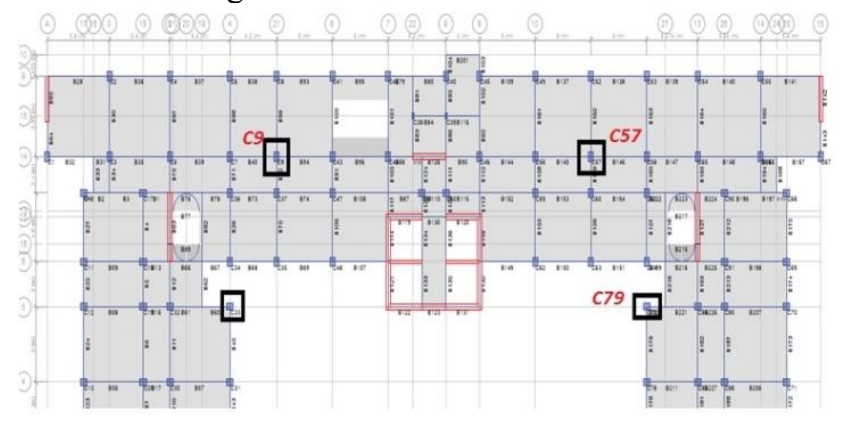

Fig. 11. Column position of C9, C57, and C79

Some failures happen at most due to axial load rather than moment. Any combinations that fails inside the curve is satisfactory, whereas any combinations falling outside the curve represents failure [13]. Figure 12 informs greater failure of column for DC system. Primarily, column at the B1 floor suffer more load which cause over capacity in axial load. Axial tension load which bring on the failure is the indication of higher seismic load subjected to DC system due to discontinuity of the system after dilatation applied.

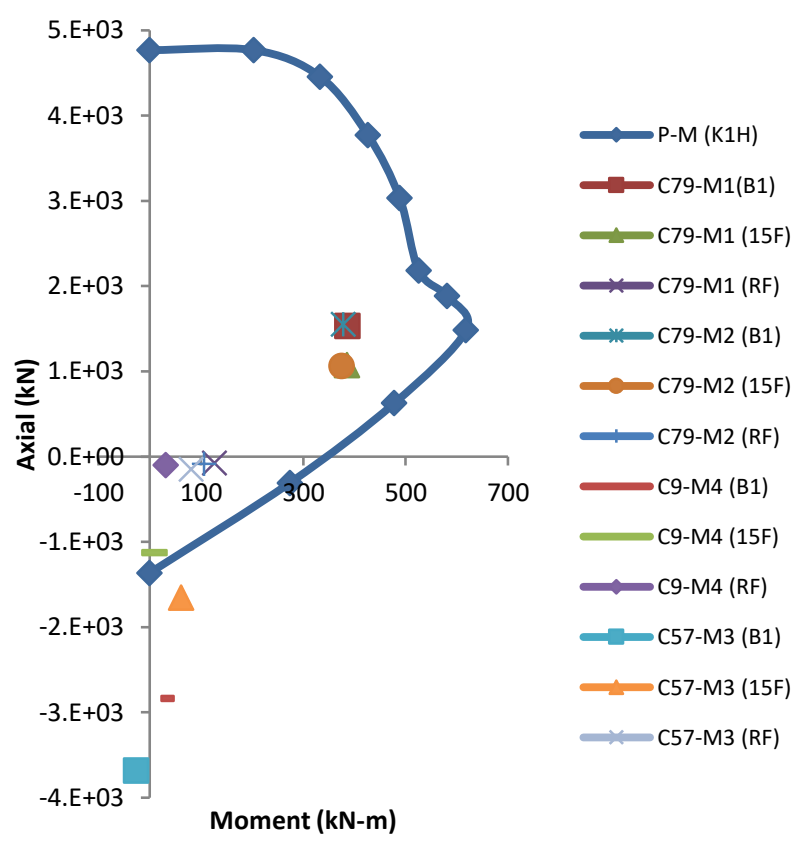

Fig. 12. P-M interaction for DC-SW model

Similarly, the capacity of the column in the basement floor of CB system is not enough to resist the load. Majority, all the columns (see figure 13) are strongly safe due to the minimum axial and moment so that $\mathrm{CB}$ that 
mean the distribution of the seismic load is uniform along the structural member. The separation of the building using CB dilatation does not create breakage of the load path distribution which is critical to the building especially the structural member like column.
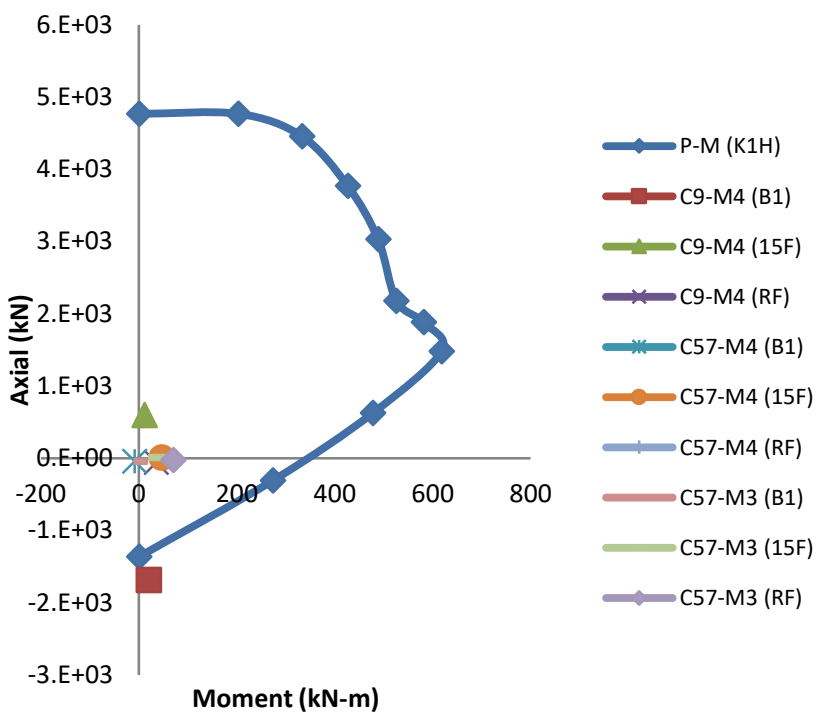

Fig. 13. P-M interaction for CB-SW model

Corresponding to the maximum displacement of the DC system, it is proven that column will undergo more horizontal load rather than CB system. Shear wall will lessen the severity of column failure for $\mathrm{CB}$ system rather than DC system due to overturning moment. Building section resulted due to disjointing by using DC system is horribly slender. This situation will create higher overturning moment so that the column at the basement floor needs to resist axial tensile load more.

\subsubsection{Beam capacity}

Distribution of load to the column will definitely relate the beam in providing great support under loading. It is distinct that beam will carry more loads on transversal direction, but the horizontal load cannot be neglected its presence in contributing failures for beam. Beam B162 represents the discussion for the beam capacity for DC and $\mathrm{CB}$ system.

Table 3. Flexure and shear capacity of beam B162

\begin{tabular}{|c|c|c|c|c|}
\hline \multirow{2}{*}{ Location } & \multicolumn{2}{|c|}{ M3-DC-SW } & \multicolumn{2}{c|}{ M4-DC-SW } \\
\cline { 2 - 5 } & $\begin{array}{c}\text { Moment } \\
k N . m\end{array}$ & $\begin{array}{c}\text { Shear } \\
k N\end{array}$ & $\begin{array}{c}\text { Moment } \\
k N . m\end{array}$ & $\begin{array}{c}\text { Shear } \\
k N\end{array}$ \\
\hline B1 & -36.02 & 41.74 & -33.21 & 42.63 \\
\hline 15F & -58.04 & 63.17 & 40.97 & 73.82 \\
\hline RF & -59.91 & 60.80 & -56.80 & 63.60 \\
\hline \multicolumn{2}{|c|}{ M3-CB-SW } & \multicolumn{2}{|c|}{ M4-CB-SW } \\
\hline B1 & 18.08 & -49.89 & 18.01 & -49.89 \\
\hline 15F & 4.67 & 20.46 & 4.63 & 20.46 \\
\hline RF & 7.49 & 69.28 & 7.48 & 69.28 \\
\hline
\end{tabular}

Moment capacity for beam indicates greater value as the story number is decreased for CB system as shown in table 3. Main difference presents for the RF as different height happens in the top floor compare to the story below. Besides, shear capacity of the beam for both M3 and M4 model does not show significant change due to uniform load transfer, otherwise DC system deviates in higher values.

\section{Conclusions}

Dilatation as the solution of breaking the irregularities problem in horizontal direction of the building plan leads to the choice of the application of double column and console beam system of U-shaped floor plan building as derived in this paper. Major discussions have managed several conclusions as below:

a. Double column system needs more consideration in arranging the column space. Larger distance will surely create excessive failure due to discontinuity of load transfer to the structural member.

b. Console beam system has the advantage of keeping the existing building into one solid structure. However, the releases of the end fixity of structural member will create the structural performance less well than the existing.

c. Irregularities in horizontal direction must concern the placement of the dilatation. Increment of irregularity in strong axis will help the structure performs better, furthermore the shear wall installation will absolutely increase the resistance of the structure under lateral load such as earthquake

d. Vertical irregularities can be well solved by using double column system due to the extra column applied for separating the corner section of the building. Console beam causes higher drift as the issue of soft story appears in the structural system.

e. Wholly, harnessing console beam system provides satisfactory result to the behaviour of structure and the capacity of member structure. Otherwise, double column system can also be considered as the accurate distance of the column solved.

\section{References}

1. C. V. R. Murthy, G. Rupen, A. R. Vijayanarayanan, and V. V. Mehta, Some Concepts in Earthquake Behavior of Buildings IITK-GSDMA Proj. Rev. Seism. Codes, Prep. Comment. Handbooks, p. 268, (2012).

2. A. Mosleh, H. Rodrigues, H. Varum, A. Costa, and A.Arêde, ISTRUC 7, pp. 1-13, (2016).

3. B. S. Nasional, Tata cara perencanaan ketahanan gempa untuk struktur bangunan gedung dan non gedung. (2012).

4. X. Zhang, Y. Qin, and Z. Chen, JCSR 116, pp. 218 232, (2016).

5. A. S. Elnashai and L. Di Sarno, Fundamentals of Earthquake, (2008).

6. K. Güler, M. G. Güler, B. Taskin, and M. Altan, 14th World Conference on Earthquake Engineering Proceeding, (2008).

7. S. Hwang, W. Lu, and H. Lee, ACI Struct. J. pp. 543552, (2000).

8. W.-F. Chen and C. Scawthorn, Earthquake Engineering Handbook, (2003). 
9. B. S. Taranath, Wind and Earthquake Resistant Buildings Structural Analysis and Design, (2005).

10. Y. Bozorgnia and V. V Bertero, Earthquake Engineering - from Engineering Seismology to Performance-Based Engineering, (2006).

11. K. Guler and M. Altan, 13th World Conference on Earthquake Engineering Proceeding, (2004).

12. M. R. Wakchaure, A. Shirish, and R. Nikam, IJIRD 1, pp. 269-281, (2012).

13. J. C. McCormac and R. H. Brown, Design of Reinforced Concrete, (2014). 